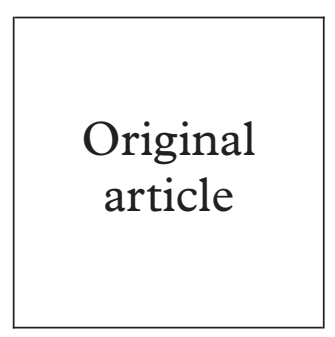

Original article

\title{
High prevalence of genital Chlamydia trachomatis infection in women presenting in different clinical settings in Jamaica: implications for control strategies
}

\author{
G Dowe, M Smikle, S D King, H Wynter, J Frederick, T Hylton-Kong
}

Objective: To determine the prevalence of genital Chlamydia trachomatis infection and risk factors in women attending family planning, gynaecology, and sexually transmitted disease (STD) clinics in Jamaica.

Methods: Endocervical specimens from 645 women including 238 family planning, 170 gynaecology, and 237 STD clinic attendees were examined for $C$ trachomatis using a direct fluorescence assay (DFA) and culture. Investigations were carried out for the presence of other STD pathogens and demographic, behavioural, historical, and clinical data recorded for each participant.

Results: The prevalence of $C$ trachomatis infection was 35\%, 47\%, and 55\% in family planning, gynaecology, and STD clinic clients, respectively. The performance of the DFA was comparable to that of culture in screening for $C$ trachomatis. Logistic regression analysis revealed that the independent risk factors for $C$ trachomatis infection were non-barrier contraceptive methods in family planning clients $(\mathrm{OR}=2.1 ; 95 \%$ confidence interval $(\mathrm{CI})=1.2-3.9 ; \mathrm{p}=0.0110)$, cervical ectopy in gynaecology clients $(\mathrm{OR}=3.9 ; 95 \% \mathrm{CI}=1.4-10.6 ; \mathrm{p}=0.0076)$ and concomitant Trichomonas vaginalis infection in STD clients $(\mathrm{OR}=3.5 ; 95 \% \mathrm{CI}=1.8-6.8 ; \mathrm{p}=0.003)$. Age, number of sex partners, and reason for visit were not identified as risk factors for $C$ trachomatis infection.

Conclusions: Consistently high prevalence of $C$ trachomatis infection occurs in Jamaican women. Universal screening or presumptive treatment should be evaluated as prevention and control measures for $C$ trachomatis infection in this population where all women appear to be at risk.

(Sex Transm Inf 1999;75:412-416)

Keywords: family planning clinics; Chlamydia trachomatis; gynaecology clinic; sexually transmitted disease clinic

\section{Introduction}

Chlamydia trachomatis is the most common sexually transmitted pathogen and an important cause of urethritis and cervicitis. ${ }^{1}$ Infection in women though often asymptomatic or mild may result in serious complications and sequelae including pelvic inflammatory disease (PID), ectopic pregnancy, and infertility, while perinatal transmission may cause neonatal conjunctivitis and pneumonia. ${ }^{2}$ Prevention and control require identifying women with asymptomatic or mild endocervical infections and those at increased risk for acquisition of $C$ trachomatis infection. ${ }^{4}$ There are several reports of reduction in the prevalence of $C$ trachomatis infection, its sequelae, and complications when screening programmes and antibiotic treatment were implemented. ${ }^{235}$ Selective screening of women for $C$ trachomatis was shown to be cost effective in sexually transmitted disease (STD) clinics, family planning clinics, and other primary healthcare settings but some studies suggest that universal screening was desirable in some situations. ${ }^{4-11}$ Presumptive treatment of people considered to be at risk for infection based on clinical symptoms and other accompanying infection was also shown to be effective in STD clinics. ${ }^{812}$ However, Pabst et $a l^{13}$ indicated the danger of merely treating women, seen in STD clinics, for reported exposure to $C$ trachomatis without further evaluation as this would fail to identify a substantial number infected with other organisms. ${ }^{13}$

A high prevalence of genital $C$ trachomatis infection has been reported in Jamaican women. ${ }^{14} 15$ In order to explore likely approaches to the control of $C$ trachomatis infection in Jamaica, we investigated its prevalence in women seen in three healthcare settings and the demographic, behavioural, and clinical factors associated with $C$ trachomatis positivity.

\section{Patients and methods}

The study population consisted of 645 women, including consecutive clients of urban family planning $(n=238$; mean age 27 years, range 16-42), gynaecology $(n=170$; mean age 25 years, range 18-36), and STD $(n=237$; mean age 30, range 12-69 years) clinics in Kingston, Jamaica. Women who had taken antibiotics within the past 4 weeks or were pregnant were excluded. After informed consent was obtained participants were interviewed according to a standardised questionnaire and subjected to physical and gynaecological examinations. The data recorded by questionnaire pertained to 
Table 1 Comparative prevalence of $C$ trachomatis by direct fluorescence assay (DFA) and culture in different clinical settings

\begin{tabular}{lllll}
\hline Clinic population & $\begin{array}{l}\text { Number } \\
\text { tested }\end{array}$ & $\begin{array}{l}\text { DFA* } \\
\text { positive (\%) }\end{array}$ & $\begin{array}{l}\text { Culture } \\
\text { positive (\%) }\end{array}$ & $\begin{array}{l}\text { Prevalence } \\
(\%) t\end{array}$ \\
\hline Family planning & 238 & $75(32)$ & $81(34)$ & $84(35)$ \\
Gynaecology & 170 & $71(42)$ & $78(46)$ & $80(47)$ \\
Sexually transmitted disease & 237 & $107(45)$ & $123(52)$ & $130(55)$ \\
Totals & 645 & $253(39)$ & $282(44)$ & $294(46)$
\end{tabular}

*The sensitivity of the DFA compared with culture was $93 \%, 91 \%$, and $87 \%$ in family planning, gynaecology, and sexually transmitted disease clients, respectively. The specificity and positive predictive values were $100 \%$ in all three groups of patients while the corresponding negative predictive values were $96 \%, 93 \%$, and $88 \%$, respectively.

†The prevalence of $C$ trachomatis infection was significantly lower in family planning clients compared with gynaecology $(\mathrm{p}=0.05)$ and sexually transmitted disease patients $(\mathrm{p}=0.001)$

age and other demographic information, medical and sexual history, current contraceptive method, current urogenital signs and symptoms, and reason for attendance at the clinic. Questionnaires were administered by three of the authors (GD, DK, and HW). The gynaecological examination included inspection of the external genitalia and speculum examination. After cleaning the ectocervix, endocervical swabs and cytobrush specimens were taken. The cytobrush specimens were examined for $C$ trachomatis by the direct fluorescence assay (DFA) (Microtrak, Syva Palo Alto, CA, USA) or McCoy cell shell vial cultures stained with fluorescent monoclonal antibodies (Syva Palo Alto, CA, USA) as previously described with modifications. ${ }^{7}$ Briefly, the swabs collected in 2SP medium were treated with amphotericin B $(10 \mu \mathrm{g} / \mathrm{ml})$ then vortexed for 30 seconds. Duplicate $0.5 \mathrm{ml}$ aliquots of $1: 2$ and $1: 4$ dilutions of the suspension were used to inoculate McCoy cells grown on coverslips in shell vials. ${ }^{7}$ After centrifugation $\left(3000 \mathrm{~g}\right.$ at $35^{\circ} \mathrm{C}$ for 1 hour) the cultures were incubated further for 1 hour at $35^{\circ} \mathrm{C}$ after which the supernatant was removed and replaced with $2 \%$ Eagle's medium containing cycloheximide. After 48 hours' incubation at $35^{\circ} \mathrm{C}$ cultures were harvested fixed in alcohol, stained with fluorescent monoclonal antibody, and examined for characteristic intracytoplasmic inclusions. A Leitz orthoplan microscope equipped with epiillumination was used to examine the coverslips at magnifications of $100 \times$ and $400 \times$. The DFA slides and fluorescent monoclonal antibody cultures were read blind by at least two people. In accordance with the manufacturer's instructions, smears containing 10 or more elementary bodies were considered positive. Standard microbiological procedures were used to examine the endocervical swab samples for Neisseria gonorrhoeae, Trichomonas vaginalis, and Candida albicans. ${ }^{1}$

STATISTICAL METHODS

Comparisons of the results were made by $\chi^{2}$ analysis and Fisher's exact two tailed test and odds ratios (OR) estimated where appropriate. To determine independent risk factors for chlamydial infection multivariate logistic regression analysis was performed using the statistical package for social sciences (SPSS). ${ }^{8}$ The risk factors chosen for analysis in the logistic regression included marital status,

Table 2 Univariate analysis of variables associated with chlamydia positivity in family planning, gynaecology and sexually transmitted disease clinic attendees in Famaica

\begin{tabular}{|c|c|c|c|c|c|c|c|c|c|}
\hline \multirow[b]{3}{*}{ Factor } & \multicolumn{9}{|c|}{ Clinic population } \\
\hline & \multicolumn{3}{|c|}{ Family planning $(n=238)$} & \multicolumn{3}{|c|}{ Gynaecology $(n=170)$} & \multicolumn{3}{|c|}{ Sexually transmitted disease $(n=237)$} \\
\hline & $\begin{array}{l}\text { Chlamydia } \\
\text { positive (\%) }\end{array}$ & $O R$ & p Value & $\begin{array}{l}\text { Chlamydia } \\
\text { positive (\%) }\end{array}$ & $O R$ & p Value & $\begin{array}{l}\text { Chlamydia } \\
\text { positive (\%) }\end{array}$ & $O R$ & p Value \\
\hline \multicolumn{10}{|l|}{ Age (years) } \\
\hline $0-14$ & $0 / 0(0)$ & & & $0 / 0(0)$ & & & $6 / 10(60)$ & & \\
\hline $15-19$ & $17 / 19(37)$ & & & $2 / 5(40)$ & & & $24 / 38(63)$ & & \\
\hline $20-24$ & $36 / 102(35)$ & & NS* & $15 / 28(54)$ & & NS & $37 / 69(54)$ & & NS \\
\hline $25-29$ & $22 / 61(36)$ & & & $19 / 52(37)$ & & & $24 / 47(51)$ & & \\
\hline$\geqslant 30$ & $19 / 56(34)$ & & & $41 / 85(48)$ & & & $39 / 73(53)$ & & \\
\hline \multicolumn{10}{|l|}{ Marital status } \\
\hline Married/cohabited & $28 / 114(27)$ & \multirow[b]{2}{*}{2.2} & \multirow[b]{2}{*}{0.04} & $36 / 87(41)$ & & \multirow[b]{2}{*}{ NS } & $48 / 92(52)$ & & \multirow[b]{2}{*}{ NS } \\
\hline Single & $56 / 124(45)$ & & & $44 / 83(51)$ & & & $78 / 145(50)$ & & \\
\hline \multicolumn{10}{|c|}{ Current contraceptive method } \\
\hline Barrier & $3 / 18(17)$ & \multirow{3}{*}{3.5} & \multirow{3}{*}{0.0001} & $3 / 13(23)$ & & \multirow{3}{*}{ NS } & $2 / 7(29)$ & & \multirow{3}{*}{ NS } \\
\hline Non-barrier & $81 / 195(42)$ & & & $25 / 46(54)$ & & & $60 / 96(62)$ & & \\
\hline None & $0 / 25(0)$ & & & $52 / 111(47)$ & & & $68 / 134(51)$ & & \\
\hline \multicolumn{10}{|c|}{ Sex partners in previous 2 months } \\
\hline $0-1$ & $82 / 228(36)$ & & \multirow{2}{*}{ NS } & $79 / 166(48)$ & & \multirow{2}{*}{ NS } & $122 / 216(56)$ & & \multirow{2}{*}{ NS } \\
\hline 2/more & $2 / 10(20)$ & & & $1 / 4(25)$ & & & $8 / 21(38)$ & & \\
\hline \multicolumn{10}{|c|}{ Previous history of sexually transmitted disease } \\
\hline Non-specific vaginit & & & & & & & & & \\
\hline Yes & $42 / 141(28)$ & \multirow[b]{2}{*}{0.6} & \multirow[b]{2}{*}{0.05} & $43 / 100(43)$ & & \multirow[b]{2}{*}{ NS } & $50 / 86(58)$ & & \multirow[b]{2}{*}{ NS } \\
\hline No & $42 / 97(43)$ & & & $37 / 70(53)$ & & & $80 / 151(53)$ & & \\
\hline \multicolumn{10}{|c|}{ Pelvic inflammatory disease } \\
\hline Yes & $13 / 35(37)$ & & \multirow[b]{2}{*}{ NS } & $17 / 39(44)$ & & \multirow[b]{2}{*}{ NS } & $49 / 62(79)$ & & \\
\hline No & $71 / 203(35)$ & & & $63 / 131(48)$ & & & $81 / 175(46)$ & 3.7 & 0.001 \\
\hline Syphilis & & & & & & & & & \\
\hline Yes & $2 / 11(18)$ & & & $0 / 0(0)$ & & & $23 / 41(56)$ & & \\
\hline No & $81 / 227(36)$ & & NS & $80 / 170(47)$ & & NS & $107 / 196(55)$ & & NS \\
\hline Gonorrhoea & & & & & & & & & \\
\hline Yes & $1 / 11(9)$ & & & $0 / 0(0)$ & & & $22 / 78(28)$ & & \\
\hline No & $83 / 227(37)$ & & NS & $89 / 170(47)$ & & NS & $108 / 159(68)$ & 0.23 & 0.0001 \\
\hline
\end{tabular}




\begin{tabular}{|c|c|c|c|c|c|c|c|c|c|}
\hline \multirow[b]{3}{*}{ Factor } & \multicolumn{9}{|c|}{ Clinic population } \\
\hline & \multicolumn{3}{|c|}{ Family planning $(n=238)$} & \multicolumn{3}{|c|}{ Gynaecology $(n=170)$} & \multicolumn{3}{|c|}{ Sexually transmitted disease $(n=237)$} \\
\hline & $\begin{array}{l}\text { Chlamydia } \\
\text { positive (\%) }\end{array}$ & $O R$ & $p$ Value & $\begin{array}{l}\text { Chlamydia } \\
\text { positive (\%) }\end{array}$ & $O R$ & p Value & $\begin{array}{l}\text { Chlamydia } \\
\text { positive (\%) }\end{array}$ & $O R$ & $p$ Value \\
\hline \multicolumn{10}{|l|}{ Urogenital manifestations } \\
\hline \multicolumn{10}{|l|}{ Genital discharges $\dagger$} \\
\hline Yes & $36 / 101(36)$ & & NS & $52 / 94(55)$ & 2.1 & 0.05 & $72 / 128(56)$ & & NS \\
\hline Yes & $12 / 136(9)$ & \multirow[b]{2}{*}{0.04} & \multirow[b]{2}{*}{0.0001} & $14 / 28(50)$ & & \multirow[b]{2}{*}{ NS } & $36 / 70(51)$ & & \multirow[b]{2}{*}{ NS } \\
\hline No & $72 / 102(71)$ & & & $66 / 142(46)$ & & & $94 / 167(56)$ & & \\
\hline \multicolumn{10}{|l|}{ Genital sores/ulcers } \\
\hline Yes & $6 / 15(40)$ & & \multirow[t]{2}{*}{ NS } & $1 / 1(100)$ & & \multirow[t]{2}{*}{ NS } & $76 / 28(57)$ & & \multirow[t]{2}{*}{ NS } \\
\hline \multicolumn{7}{|l|}{ Vulval pruritus } & & & \\
\hline Yes & $20 / 79(25)$ & & \multirow[b]{2}{*}{ NS } & $20 / 43(47)$ & & \multirow[b]{2}{*}{ NS } & $59 / 116(51)$ & & \multirow[b]{2}{*}{ NS } \\
\hline No & $64 / 159(40)$ & & & $60 / 127(47)$ & & & $71 / 121(59)$ & & \\
\hline \multicolumn{10}{|l|}{ Lower abdominal pain } \\
\hline Yes & $31 / 91(34)$ & & \multirow[b]{2}{*}{ NS } & $37 / 74(50)$ & & & $61 / 119(51)$ & & \\
\hline No & $53 / 147(36)$ & & & $43 / 96(45)$ & & NS & $69 / 118(58)$ & & NS \\
\hline Cervical friability & & & & & & & & & \\
\hline Yes & $10 / 21(48)$ & & NS & $8 / 11(73)$ & & NS & $28 / 56(50)$ & & NS \\
\hline $\begin{array}{l}\text { No } \\
\text { Cervical ectopy }\end{array}$ & $74 / 217(34)$ & & & $72 / 159(45)$ & & & $102 / 181(52)$ & & \\
\hline Yes & $14 / 36(39)$ & & & $16 / 20(80)$ & & & $47 / 88(53)$ & & \\
\hline No & $70 / 202(35)$ & & NS & $64 / 150(43)$ & 5.4 & 0.05 & $83 / 149(56)$ & & NS \\
\hline Concurrent non-chlamydial genital infection & & & & & & & & & \\
\hline $\begin{array}{l}\text { Gonorrnoea } \\
\text { Yes }\end{array}$ & $1 / 1(100)$ & & & $0 / 0(0)$ & & & $4 / 40(10)$ & & \\
\hline No & $83 / 237(35)$ & & NS & $80 / 170(47)$ & & NS & $126 / 197(64)$ & 0.06 & .0001 \\
\hline Syphilis & & & & & & & & & \\
\hline Yes & $1 / 1(100)$ & & & $0 / 0(0)$ & & & $12 / 24(50)$ & & \\
\hline No & $83 / 237$ (35) & & NS & $80 / 170(47)$ & & NS & $118 / 213(55)$ & & NS \\
\hline Trichomonas vaginalis & & & & & & & & & \\
\hline Yes & $5 / 19(26)$ & & NS & $11 / 14(79)$ & 46 & 005 & $38 / 56(68)$ & 2 & 005 \\
\hline $\begin{array}{l}\text { No } \\
\text { Candidiasis }\end{array}$ & $79 / 219(36)$ & & NS & $69 / 156(44)$ & 4.6 & 0.05 & $92 / 181(51)$ & 2.10 & 0.05 \\
\hline Yes & $20 / 38(53)$ & & & $10 / 17(59)$ & & & $19 / 31(61)$ & & \\
\hline No & $64 / 200(32)$ & 2.4 & 0.05 & $71 / 153(46)$ & & NS & $121 / 206(59)$ & & NS \\
\hline $\begin{array}{l}\text { Reason for attendance } \\
\text { Genitourinary symptoms }\end{array}$ & & & & & & & & & \\
\hline Genitourinary symptoms & $59 / 173(34)$ & & & $62 / 131(47)$ & & & $103 / 196(53)$ & & \\
\hline Sexually transmitted disease contact & $0 / 0(0)$ & & NS & $1 / 1(100)$ & & NS & $21 / 33(64)$ & & NS \\
\hline Routine consultation $\ddagger$ & $25 / 65(38)$ & & & $18 / 38(47)$ & & & $6 / 8(75)$ & & \\
\hline
\end{tabular}

${ }^{\star} \mathrm{NS}=\mathrm{p}$ value not significant

†Genital discharges were observed by the clinician and included 2 cases of mucopurulent discharge in gynaecology clients.

†Includes clients visiting for infertility, Pap smear, post surgery check family planning consultations.

contraceptive method, dysuria, co-infection with Candida albicans, and non-specific vaginitis in family planning clients; genital discharge, cervical ectopy, and co-infection with Trichomonas vaginalis in women attending gynaecology clinics; and co-infection with $N$ gonorrhoeae, co-infection with $T$ vaginalis, previous history of gonorrhoea, and previous history of pelvic inflammatory disease in clients attending STD clinics.

\section{Results}

A total of 645 women drawn from the family planning, gynaecology, and STD clinic populations were screened for $C$ trachomatis infection by the DFA and culture. As shown in table 1 . Using the DFA $C$ trachomatis was detected in $39 \%(253 / 645)$ of the women, $44 \%(282 / 645)$ were positive by culture and $46 \%(294 / 645)$ were positive by either or both methods. The prevalence of $C$ trachomatis infection in the family planning clinic attendees $(35 \% ; 84 / 238)$ was statistically significantly lower than that observed in women who attended the gynaecology $(47 \%, 80 / 170 ; p=0.05)$ and STD clinics $(130 / 237,55 \%$; $p=0.001)$. The DFA was less sensitive than culture but the differences were not statistically significant. The specificity and positive predictive value of the DFA were $100 \%$ in the three clinic populations. The most frequent urogenital manifestation in the family planning clients was dysuria $(136 / 238,57 \%)$ but clients with dysuria accounted for only $14 \%(12 / 84)$ of the chlamydial isolates. The results of univariate analysis of demographic, behavioural, and clinical factors and $C$ trachomatis positivity in the three groups of women are summarised in table 2 . In the family planning clinic population the prevalence of $C$ trachomatis was statistically significantly increased in clients who were single $(56 / 135,41 \%)$ compared with those who were married or cohabited $(28 / 114 \%, 27 \%$; OR=2.2; $\mathrm{p}=0.04)$; used non-barrier methods of contraceptive 
$(81 / 195,42 \%)$ compared with barrier methods $(3 / 18,17 \% ; \mathrm{OR}=3.5 ; \mathrm{p}=0.0001)$ and those with current genital candidiasis $(20 / 38,53 \%)$ compared with those without $(64 / 200,32 \%$; $\mathrm{OR}=2.4 ; \mathrm{p}=0.05)$. Also in this group the frequency of $C$ trachomatis infection was significantly decreased in women with previous history of non-specific vaginitis $(42 / 141,28 \%)$ compared with those without (42/97, 43\%; $\mathrm{OR}=0.60 ; \mathrm{p}=0.05)$ and women with dysuria $(12 / 136 ; 9 \%)$ compared with those without $(72 / 102,71 \%$; OR $=0.04 ; \mathrm{p}=0.0001)$. In the gynaecology clinic population the frequency of positive tests for $C$ trachomatis was statistically significantly increased in women with genital discharges as observed by the clinician (52/94, $55 \%)$ compared with those without $(28 / 76$, $37 \% ; \mathrm{OR}=2.1 ; \mathrm{p}=0.05)$; cervical ectopy $(16 /$ $20 ; 80 \%)$ compared with those without (64/ $150,43 \%$; OR=5.4; $\mathrm{p}=0.05)$; and women co-infected with $T$ vaginalis $(11 / 14,79 \%)$ compared with those who were not $(69 / 156$, $44 \%$; OR $=4.6 ; \mathrm{p}=0.05)$. In the women attending STD clinics, $C$ trachomatis positivity rates were statistically significantly increased in women who had a previous history of PID (49/ $62,79 \%)$ compared with those who did not $(81 / 175,46 \% ; \mathrm{OR}=3.7 ; \mathrm{p}=0.001)$ and those with current $T$ vaginalis infection $(38 / 56,68 \%)$ compared with those without (92/181, 51\%; $\mathrm{OR}=2.1 ; \mathrm{p}=0.05)$. Statistically decreased prevalence were found in those with previous history of gonorrhoea $(22 / 78,28 \%)$ compared with those without $(108 / 159,68 \%$; OR $=0.23$; $\mathrm{p}=0.0001)$ and women with current gonorrhoea $(4 / 40 ; 10 \%)$ compared with those without $(126 / 197 ; 64 \% ; O R=0.06 ; p=0.0001)$. Logistic regression analysis revealed that the independent risk factors for $C$ trachomatis infection were non-barrier contraceptive methods in family planning clients $(\mathrm{OR}=2.1 ; 95 \%$ confidence interval $(\mathrm{CI})=1.2-3.9 ; \mathrm{p}=0.0110)$, cervical ectopy in gynaecology clients $(\mathrm{OR}=3.9 ; 95 \% \mathrm{CI}=1.4-10.6 ; \mathrm{p}=0.0076)$ and concomitant $T$ vaginalis infection in STD clients $(\mathrm{OR}=3.5 ; 95 \% \mathrm{CI}=1.8-6.8 ; \mathrm{p}=0.003)$. No significant correlations were observed with age, number of sex partners in the previous 2 months, pelvic pain, vulval pruritus, genital ulcers, cervical friability, current syphilis or previous history of syphilis, or reason for attendance in any clinic.

\section{Discussion}

The high prevalence of $C$ trachomatis infection within these distinct groups of Jamaican women strongly supports observations made in previous studies. ${ }^{14} 15$ The current finding of a $35 \%$ prevalence of $C$ trachomatis in family planning clients and the previously reported $16 \%$ prevalence in pregnant Jamaican women suggest that the general female population is at risk and contradicts assumptions that these groups represent low risk categories. ${ }^{15}$ The lower prevalence of $C$ trachomatis reported in Jamaican commercial street sex workers $24 \%$ compared with the family planning clinic clients in this study (35\%) could be explained by more use of barrier contraceptive methods in the former group. In fact, the incidence of $C$ trachomatis infection observed in the three groups of women in this study exceeds that from most reported studies whether or not the study was conducted in a developing or developed country. ${ }^{41316} 17$ The high prevalence of $C$ trachomatis in Jamaican women attending family planning and gynaecology clinics may be attributed to treatment seeking practices. For economic reasons, Jamaican women who are enrolled in family planning clinics initially may seek treatment at those clinics for other health problems. Similarly, because of the social stigma, Jamaican women with symptoms of STD would seek treatment at gynaecology clinics rather than STD clinics. The often mild or asymptomatic disease course, the absence of partner notification and subsequent nontreatment of sexual partners for $C$ trachomatis may also contribute to the reported high prevalence.

In the United States, the national recommendation is universal screening for $C$ trachomatis in populations with prevalence of or exceeding $10 \%$ and treating $C$ trachomatis positive women and their partners. Nevertheless, we carried out univariate and multivariate analyses of our data to identify independent risk factors for infection in the three clinical groupings. Perhaps the most striking finding from the analysis was that the factors which significantly correlated with current $C$ trachomatis infection varied with each clinic population. This might be due to clinical and behavioural differences in the three groups of women. In agreement with other studies non-barrier contraceptive methods were independently associated with $C$ trachomatis in the family planning clients. ${ }^{711}$ There are few documented studies of $C$ trachomatis infection in a gynaecological setting. ${ }^{2}{ }^{18}$ In this study cervical ectopy was an independent risk factor for $C$ trachomatis infection in gynaecological patients but not in the other groups of women. Several authors have reported cervical ectopy as a risk factor for chlamydia in gynaecological patients and other groups of women. ${ }^{71219}$ Co-infection with $T$ vaginalis was the only independent risk factor for chlamydial infection in STD clients. In similar studies $T$ vaginalis infection and previous history of PID have been reported as independent risk factors for $C$ trachomatis infection. ${ }^{7812}{ }^{13}$ Others have reported higher $C$ trachomatis positivity rates in patients with concurrent gonorrhoea but this was not observed in this or other studies of Jamaican women. ${ }^{4121315}$ This observation was in conflict with the current practice of co-treatment of chlamydia in patients diagnosed with gonorrhoea and the syndrome based management of cervical infections recommended by the World Health Organisation (WHO). ${ }^{16}{ }^{19}$ In the univariate analysis genital discharges on examination correlated with $C$ trachomatis infection in gynaecology clinics. Contradicting other studies this was not an independent risk factor despite being the most common urogenital manifestation in the three clinic populations. ${ }^{4}$ Recognising the limited laboratory facilities available for diagnosis of cervical infections in developing countries, 
Behets et al recently compared the use of diagnostic algorithms with laboratory testing in the management of vaginal discharge in women seen at a Jamaican STD clinic. ${ }^{19}$

Several independent predictors of $C$ trachomatis infection, reported by others as useful components of screening strategies, were not identified in this study. For example, age based selective screening in some populations is advocated but the protective effect of increasing age on $C$ trachomatis infection consistently reported by others was not observed in this study. ${ }^{416}$ A previous report of Jamaican commercial street sex workers identified age as the only risk factor for $C$ trachomatis infection. Several of the factors-for example, age and number of sex partners, which did not correlate with $C$ trachomatis infection in this study had been reported by Behets et al to be risk factors for cervical infection in Jamaican women attending STD clinics. ${ }^{19}$ Similarly, in some studies reason for visit correlated with $C$ trachomatis positivity but was not identified as a risk factor in our study. ${ }^{41316}$ The failure to identify age, number of sex partners, and reason for visit as risk factors in this study, as in others, may be attributed to uniformity of these factors in the women studied and the high prevalence of $C$ trachomatis infection.

The similarly high prevalence of $C$ trachomatis noted in both symptomatic and asymptomatic women in Jamaica suggests that universal screening or preventive treatment rather than selective screening may be the more effective control measure in that population. Our observations affirm the need for assessment of each clinical population and separate evaluations for each STD pathogen in the design of screening programmes. This study confirms the efficacy of the DFA for chlamydial screening in different clinical settings but did not consider the cost effectiveness of this method for universal screening in Jamaica. The efficacy of less labour intensive methods of chlamydial screening such as the EIA should also be evaluated for universal screening of Jamaican populations. Further studies are needed but presumptive treatment may be the best approach to the prevention and control of $C$ trachomatis infection in countries such as Jamaica where prevalence is high and healthcare budgets limited.
Contributors: HW, JF, and TH-K were the clinical collaborators in the family planning, gynaecology, and STD clinics, respectively; the questionnaires were administered by GD, SDK, and HW; GD, MS, SDK were responsible for the performance of the microbiological procedures and preparation of the manuscript.

1 Dowe G, King SD, Smikle MF, et al. Prevalence of viral and bacterial sexually transmitted pathogens in Jamaican pregnant women. W Indian Med f 1998;47:23-5.

2 Sciarra JJ. Sexually transmitted diseases: global importance. Int F Gynaecol Obstet 1997;58:107-19.

3 Chlamydia trachomatis genital infections-United States, 1995. MMWR 1997;46:1983-8.

4 Addis DG, Vaughn ML, Golubjatnikov R, et al. Chlamydia trachomatis infection in women attending urban midwestern family planning and community health clincs: risk facern family planning and community health clincs: risk fac-
tors, selective screening and evaluation of non-culture tors, selective screening and evaluation of
techniques. Sex Transm Dis 1996;17:138-44.

5 Howell MR, Quinn TC, Gaydos CA. Screening for Chlamydia trachomatis in asymptomatic women attending family planning clinics. A cost-effectiveness analysis of three strategies. Ann Intern Med 1998;128:277-84.

6 Marrazzo JM, Fine D, Celum CL, et al. Selective screening for chlamydial infection in women: a comparison of three sets of criteria. Fam Plann Perspect 1997;29:158-62.

7 Stergachis A, Scholes D, Heidrich FE, et al. Selective screening for Chlamydia trachomatis infection in a primary care population of women. Am $\mathcal{F}$ Epidemiol 1993;38:14353.

8 Kent GP, Harrison HR, Berman SM, et al. Screening for Chlamydia trachomatis infection in a sexually transmitted disease clinic: comparison of diagnostic test with clinical and historical risk factors. Sex Transm Dis 1988;15:51-7.

9 Wasti S, Ashfaq MK, Islag R, et al. Prevalence of chlamydial infection in women attending antenatal and family planning clinics in Karachi, Pakistan. Aust NZ f Obstet Gynaecol 1997;37:462-5.

10 Mosure DJ, Berman S, Fine D, et al. Genital chlamydia infections in sexually active female adolescents: do we really need to screen everyone? F Adolesc Health 1997;20:613.

11 Weinstock HS, Bolan GA, Kohn R, et al. Chlamydia trachomatis infection in women: a need for universal screening in high prevalence populations. Am f Epidemiol 1992;135:417 .

12 Magder LS, Harrison RH, Ehret JM, et al. Factors related to genital Chlamydia trachomatis and its diagnosis by culture in a sexually transmitted disease clinic. Am $\mathcal{F}$ Epidemiol 1988;128:298-308.

13 Pabst KM, Reechart CA, Knud-Hansen CR, et al. Disease prevalence among women attending a sexually transmitted disease clinic varies with reason for visit. Sex Transm Dis 1992;19:88-91.

14 King SD, Dowe G, Wynter HH, et al. Chlamydial infections in selected populations in Jamaica. W Indian Med $f$ 1992;42:136-8.

15 Dowe G, King SD. Genital Chlamydia trachomatis (serotypes D-K) infection in Jamaican commercial street (serotypes D-K) infection in Jamaican com

16 Humphreys JT, Henneberry JF, Rickard RS, et al. Cost benefit analysis of selective screening criteria for Chlamydia trachomatis infection in women attending Colorado family planning clinics. Sex Transm Dis 1992;19:47-53.

17 Theunissen JJ, Kariwiga G, Ossewaarde JM, et al. Prevalence of Chlamydia trachomatis in women attending a family planning clinic in Papua New Guinea. Genitourin Med 1995;71:295-6.

18 Dieterle S. Chlamydia infections in gynaecology and obstetrics. Geburtshilfe und Frauenheilkunde 1995;55:510-17.

19 Behets FMT, Williams Y, Braithwaite A, et al. Management of vaginal discharge in women treated at a Jamaican sexually transmitted disease clinic: use of diagnostic algorithms versus laboratory testing. Clin Infect Dis 1995;21:1450-5. 